\title{
La calidad de las relaciones con los medios de comunicación y su impacto en los contenidos periodísticos
}

Recibido: 06 de noviembre de 2014

Aceptado: 01 de julio de 2015

Publicado: 30 de octubre de 2015
Karen Cortez Gaona

kcortezg@usmp.pe

Universidad de San Martín de Porres (Perú)

Resumen: Esta investigación aborda una de las funciones del ejercicio de las Relaciones Públicas: la gestión con los medios de comunicación. Sustentada en la relación ética y colaborativa con los medios periodísticos, se demuestra la correlación que existe entre la calidad de las relaciones con los medios periodísticos desde una organización del sector educación con la publicación de contenidos periodísticos sobre esta, según los niveles de confianza, satisfacción y compromiso vinculados en su razón como fuente periodística, relevancia periodística de los contenidos y/o eventos de la organización; así como la realidad mediática construida por los medios periodísticos impresos. Este estudio descriptivo-correlacional, no experimental y cuali-cuantitativo demuestra que la calidad de las relaciones sí influye en los contenidos periodísticos. Sobre la base de los resultados hallados, se afirma que existe un nivel de correlación de $71.8 \%$, lo cual es un claro indicador de alto nivel que existente entre las variables.

Palabras claves: Relaciones públicas, calidad de relaciones, medios de comunicación, relación con medios periodísticos, periodistas.

Abstract: This research addresses one of the functions of public relations exercise: management with the media. Supported by the ethical and collaborative relationship with the media the correlation between the quality of relations with the media from an organization with the publication of newspaper media on this, according to the levels of trust, satisfaction and commitment demonstrated linked in his reason as a journalistic source, journalistic relevance of the content and / or events of the organization; and the reality constructed by the media print news media investigated: El Comercio, Gestion, Perú 21, La República, Correo, La Primera y Expreso. This descriptive-correlational, not experimental, qualitative and quantitative research shows that the quality of relationships does influence news content. Based on the results found, it is stated that 
there is a correlation level of $71.8 \%$, which is a clear indicator of high-level existing between the variables.

Key words: Public Relations, Quality of Relationships, Media, Relationship with Media, Journalists.

\section{Introducción}

Este artículo aborda el quehacer de las RR. PP. desde la gestión con los medios periodísticos, campo de acción que se analiza desde la calidad de las relaciones que las instituciones universitarias construyen con los medios periodísticos y cómo estos últimos se relacionan con el tratamiento informativo en razón de la organización, siendo esta del sector educación, fuente de conocimiento e investigación académica y especializada.

Los medios periodísticos juegan un papel fundamental en la construcción de la imagen y consolidación de la reputación de las organizaciones, por lo que mantener una buena relación con ellos es producto de la aplicación de estrategias de RR. PP. y un accionar ético basado en la confianza y respeto hacia el trabajo periodístico. Es así que, tener amigos periodistas, ofrecerles almuerzos, cenas y/o regalos no es la clave para generar apariciones mediáticas y proyectar el mejor ángulo informativo de una organización.

Un aspecto esencial dentro de toda planificación de RR. PP. es la interacción entre los diversos medios de comunicación escritos, audiovisuales, digitales y el relacionista público de una organización; quien al convertirse en pieza clave para la producción de noticias periodísticas creíbles y de interés para la opinión pública, tiene la gran oportunidad de sumarse a la lista de fuentes informativas para los medios periodísticos, los cuales gozan de confiabilidad y veracidad para los periodistas que construyen, editan y finalmente aprueban los contenidos para su publicación. En ese sentido, el profesional tiene la responsabilidad de explorar, conectar y sintonizar con los diversos medios de comunicación, cada vez más segmentados y especializados, mediante un trabajo ético y profesional, fundamentado en la entrega de información veraz, transparente, sistemática y sostenible. De esta forma, los contenidos enviados por las organizaciones a los medios periodísticos serán apreciados por su valor noticioso y no como mera publicidad.

Algunas organizaciones no cuentan con políticas y programas de relación y comunicación con los públicos objetivos, entre estos, los medios periodísticos. La restricción de la información y rechazo hacia los medios (por parte de las organizaciones) es recurrente, lo cual no contribuye en la proyección de una imagen de organización de "puertas abiertas" y revela, por el contrario, que las organizaciones buscan contactar con los medios y periodistas solo cuando desean anunciar algún evento que, para su opinión, debe ser publicable y de interés general, sin tomar en cuenta si la información cumple con los criterios periodísticos.

Una positiva relación con los medios demanda entendimiento, empatía y conocimiento de su labor para que la organización sea efectiva cuando busca difundir un hecho que 
considera trascendente. Por lo general, las organizaciones asumen que todo lo que hacen puede generar noticia. Sin embrago, La Rosa (2013: 16) afirma lo siguiente:

"Son los periodistas, a partir de los datos sobre la realidad proporcionados por diversas fuentes de información, y el trabajo del personal de su organización, quienes se encargan de seleccionar aquello que consideran de mayor trascendencia; para hacerlo bajo criterios prestablecidos, configurados, reforzados y reformulados por la práctica cotidiana, para presentarlo finalmente a la audiencia".

Este artículo analizará en qué medida la calidad de las relaciones de las organizaciones universitarias con los medios periodísticos influyen con las publicaciones periodísticas sobre ellas.

\section{Objetivos}

\subsection{Objetivo general}

Determinar si la calidad de las relaciones de una organización de educación universitaria con los medios de comunicación tiene relación significativa con las publicaciones periodísticas realizadas sobre esta.

\subsection{Objetivos específicos}

- Analizar si el nivel de confianza de los medios periodísticos con la organización de educación universitaria tiene relación significativa para considerarla como fuente periodística.

- Evaluar si el nivel de compromiso de los medios periodísticos tiene relación significativa con la construcción de la realidad mediática de la organización de educación universitaria.

- Determinar si el nivel de satisfacción de los medios periodísticos tiene relación significativa con la relevancia periodística de los contenidos enviados por la organización de educación universitaria.

\section{Metodología}

En la presente investigación se ha establecido la relación entre dos variables y sus respectivas dimensiones: calidad de las relaciones y contenidos periodísticos, desde la perspectiva de la comunicación y Relaciones Públicas.

De acuerdo con Hernández, Fernández y Baptista (2003), la presente investigación es de tipo correlacional no experimental, por cuanto este tipo de estudios tiene como propósito evaluar 
la relación que existe entre dos o más conceptos, categorías o variables en un contexto natural sin manipulación intencional. Es cuantitativa porque los datos están representados a través de un estudio numérico, es decir, a través de métodos estadísticos que han analizado la información obtenida, a través de encuestas según escala de Likert realizada a la población en un determinado contexto; y es cualitativa porque se ha realizado otro proceso de recolección de datos no estandarizados como la observación, la cual no se somete a estudios numéricos de métodos estadísticos, si no a la interpretación y análisis de la información recolectada.

El método de investigación es deductivo, porque va de lo general a lo específico. En este caso, porque permite establecer políticas de comunicación institucional desde una organización universitaria y poder trabajar con en el resto de las universidades para la construcción de su imagen y consolidación de su reputación. El método inductivo permite recomendar soluciones estratégicas a las diferentes universidades mediante la relación con los medios periodísticos.

La investigación se realizó en Lima Metropolitana y la población está constituida por 106 periodistas, entre los cuales se encuentran editores, jefes de información y periodistas con poder de decisión en elegir los temas a publicar de los medios periodísticos impresos y 4 relacionistas públicos del área de comunicaciones de la organización estudiada. El tamaño de la muestra se ha determinado mediante la fórmula que nos permite establecer que la muestra está conformada por 83 periodistas. Para ejecutar la recolección de la información, se diseñó un cuestionario y una ficha de observación para los impactos periodísticos de diversos medios impresos sobre la organización estudiada.

Sobre la validez y confiabilidad de estos instrumentos, el cuestionario ha sido validado por el juicio de expertos y se ha otorgado la denominación de bueno (95\%) al instrumento que mide la calidad de las relaciones institucionales universitarias en relación a los contenidos publicados en los medios periodísticos. Para ello, se utilizó la prueba de confiabilidad de alfa de Cronbach para estimar la consistencia interna del cuestionario, el cual arrojó un valor de 0.805 , lo cual indica que el instrumento utilizado es confiable.

Sobre la técnica para el procesamiento de la información, el estudio empleó el programa informático estadístico SPSS (Statistical Package for the Social Sciences, Paquete Estadístico para las Ciencias Sociales) programa desarrollado por la Universidad de Chicago. Su uso resultó conveniente porque contiene todos los análisis estadísticos requeridos para esta investigación: informes, estadísticos descriptivos, comparación de medidas, correlaciones, regresiones, clasificación, reducción de datos, escalas, pruebas no paramétricas, respuestas múltiples, validación compleja, series de tiempos, ecuaciones, etc.

Para la tabulación de los resultados obtenidos mediante el instrumento se utilizó el programa Microsoft Excel 2007, luego se trasladaron los datos a SSPS 20, se realizó el análisis descriptivo de los ítems y para decidir las correlaciones se determinó el estadígrafo a utilizar mediante el test de Kolmorogov-Smirnov que permite establecer la normalidad de la distribución y en este caso se determinó que la distribución no es normal, por tanto se usó la prueba de correlación Rho de Spearman. 
Figura 1: Variable calidad de las relaciones y publicación de contenidos periodísticos.

\begin{tabular}{|c|c|c|}
\hline VARIABLES & DIMENSIONES & INDICADORES \\
\hline \multirow{3}{*}{$\begin{array}{l}\text { CALIDAD DE LAS } \\
\text { RELACIONES }\end{array}$} & Confianza & $\begin{array}{l}\text { - Integridad. } \\
\text { - Confiabilidad. } \\
\text { - Competencia. }\end{array}$ \\
\hline & Compromiso & $\begin{array}{l}\text { - Compromiso continuidad. } \\
\text { - Compromiso afectivo. }\end{array}$ \\
\hline & Satisfacción & $\begin{array}{l}\text { - Beneficio } \\
\text { - Cubrir necesidades y expectativas }\end{array}$ \\
\hline \multirow{3}{*}{$\begin{array}{l}\text { PUBLICACIÓN } \\
\text { DE CONTENIDOS } \\
\text { PERIODÍSTICOS }\end{array}$} & $\begin{array}{l}\text { Fuente } \\
\text { periodistica }\end{array}$ & $\begin{array}{l}\text { - Cumplimientos con criterios de selección. } \\
\text { - Cumplimiento con los valores noticiosos. } \\
\text { - Cumplimiento con los criterios periodísticos. }\end{array}$ \\
\hline & $\begin{array}{l}\text { Relevancia } \\
\text { periodística }\end{array}$ & $\begin{array}{l}\text { - Cumplimiento con los criterios de } \\
\text { noticiabilidad. } \\
\text { - Número de cobertura periodística. } \\
\text { - Número de publicaciones periodísticas. }\end{array}$ \\
\hline & $\begin{array}{l}\text { Construcción } \\
\text { de la realidad } \\
\text { mediática }\end{array}$ & $\begin{array}{l}\text { - } \text { Sistema de valores. } \\
\text { - } \text { Rutinas de producción. } \\
\text { - Niveles de decisión. } \\
\text { - Criterios de calidad. } \\
\text { - Criterio de oportunidad. } \\
\text { - Criterio de pertinencia. }\end{array}$ \\
\hline
\end{tabular}

Fuente: Elaboración propia.

\section{Hipótesis de trabajo}

\subsection{Hipótesis general}

La calidad de las relaciones de una organización universitaria con los medios de comunicación tiene relación significativa con las publicaciones periodísticas realizadas sobre esta. 


\subsection{Hipótesis específicas}

- El nivel de confianza de los medios periodísticos con la organización universitaria tendría relación significativa para considerarla como fuente periodística.

- El nivel de compromiso de los medios periodísticos tendría relación significativa con la construcción de la realidad mediática de la organización universitaria.

- El nivel de satisfacción de los medios periodísticos tendría relación significativa con la relevancia periodística de los contenidos enviados por la organización universitaria.

\section{La calidad de las relaciones desde las organizaciones universitarias con los medios}

La gestión con los medios periodísticos es una de las funciones de las RR. PP. que goza de una particular atención por ser la ventana principal hacia la opinión pública y son denodados los esfuerzos en los que incurren las organizaciones para lograr un espacio visible que les permita construir una imagen positiva. Para lograr este propósito, son las RR. PP. las encargadas de direccionar esta gestión mediante un proceso de relación y comunicación fundamentada en la confianza y la satisfacción mutua como resultado de un proceso planificado. El comportamiento ético organizacional juega un papel fundamental para mantener y consolidar una buena reputación en sus públicos, como los medios de comunicación en sintonía con los diversos programas de RR. PP. y los objetivos organizacionales. En ese sentido, Grunig y otros (2002) aseguran que existe una mayor valoración de las RR. PP. porque se entiende que las comunicaciones se articulan con otras funciones de gestión para construir una buena relación a largo plazo con las partes interesadas.

Los medios de comunicación gravitan junto con las organizaciones dentro de un mercado especializado y competitivo en una sociedad cada vez más compleja, exigente y global. En ese sentido, las organizaciones se sustentan en las RR. PP. al ser "una disciplina cuya finalidad superior es promover la integración social y humana en su más alta expresión" (Pereira y Flores, 2010: 67), y se apoyan en otras disciplinas de las ciencias sociales para comprender sus dimensiones, así como para gestionar las relaciones con los públicos. Según Ferrari y França (2012) son esenciales los conceptos extraídos de las teorías de la sociología y de la administración.

En ese grupo, la "teoría social de sistemas" (Kuhn, 1990) es particularmente importante para entender los sistemas, los procesos y las prácticas de las RR. PP. y que la postura de Pavlik (1987), sobre la teoría de sistemas está cerca de ser considerada un paradigma para las RR. PP. (Ferrari y França, 2012). Son ambas teorías, sus procesos y prácticas las 
que promueven la adaptación, el entendimiento mutuo y la comunicación de doble vía, finalidad prima entendida por Pérez y Solórzano (1999: 25) y que puede lograrse mediante la siguiente definición: "para las RR. PP. administrar es estudiar, describir y explicar, el gran escenario social donde interaccionan los diferentes públicos, proporcionando criterios suficientes para que las organizaciones puedan escoger y decidirse por alternativas relacionales debidamente fundamentadas, que den legitimidad a sendos mensajes en los procesos comunicativos".

Las RR. PP. (dentro de su función frente a los medios de comunicación) buscan convertir a la organización en una fuente de información confiable, fidedigna, fluida, inmediata e inagotable en los temas a los cuales se encuentran vinculada. En ese sentido, y tratándose de una organización universitaria, fuente de conocimientos y de investigación; cualidad que se convierte en una fortaleza para la consolidación de su reputación a través del tratamiento periodístico y repercusión mediática.

Los expertos afirman que "la confianza relacional mutua es apoyada por información con credibilidad que da acceso al conocimiento y legitimada por un nivel moral de comportamiento" (ibídem) y tratándose de una organización de educación, la información especializada que proporcione cuenta con mayor credibilidad porque sus enunciados se sustentan en la investigación y promoción de la ciencia, tecnología y cultura, y su comportamiento se fundamenta en la formación de profesionales competentes con valores humanísticos, éticos y morales para la construcción de una sociedad moderna y equitativa.

Lograr esa sintonía entre la organización y los medios periodísticos responde a una labor estratégica a cargo de profesionales de las RR. PP. que posean aptitudes y conocimientos para la elaboración, ejecución, control y evaluación de planes y programas de RR. PP. Pereira y Flores (2010: 71) enuncian las siguientes funciones para el diseño y desarrollo de programas de esta disciplina:

"Investigar las actitudes y opiniones de los públicos, formular diagnósticos situacionales, pronosticar conductas sociales, administrar la comunicación interna y externa, negociar con los públicos, asesorar a los directivos de cualquier organización, proyección y control de la imagen, y la formulación de políticas de comunicación y relaciones humanas para la toma de decisiones que favorezcan la creación de un óptimo clima psicosocial al interior de la organización, y una relación de comprensión y confianza con los públicos externos, tendentes a la plena integración del organismo social corporativo".

Sobre estas funciones, Wilcox, Cameron y Xifra (2006) traen a colación la Declaración de Principios de la Sociedad de Relaciones Públicas de América, añadiéndose los siguientes puntos: a) anticipar, analizar e interpretar la opinión pública, actitudes y temas que pueden afectar los planes de la organización; $b$ ) asesorar a todos los niveles de dirección respecto a las decisiones políticas, pautas de acción y comunicación, considerando las consecuencias públicas y sociales; $c$ ) investigar y evaluar de forma permanente los 
programas de acción y comunicación para la comprensión pública; $d$ ) planificar y aplicar los esfuerzos para influir o cambiar la política pública; e) definir objetivos, f) realizar presupuestos, $g$ ) contratar y formar al personal; y $h$ ) gestionar los recursos para realizar todo enumerado.

En la construcción de la relación con los medios de comunicación, la persuasión es indispensable, por lo que Cuptip y Center condensan (en siete puntos) los factores clave para alcanzar este objetivo: a) credibilidad argumentada como fuente informativa y de utilidad al receptor quien ha de conferir confianza como experto en concordancia entre lo que dice y hace; b) contexto adaptado a las realidades del entorno local que permita la participación y el diálogo para alcanzar una atmósfera de tranquilidad; c) contenido informativos y prometedores para los públicos y que a la vez sean más noticiables pues generarían un "publicity" adicional; $d$ ) claridad de los mensajes redactados con sencillez, pues el significado final tendrá que ser el mismo para el receptor que para el transmisor; $e$ ) continuidad y consistencia de la comunicación mediante un proceso reiterativo que logre aceptación y efectos persuasivos; $f$ ) debe ser sostenible para que sea aceptado en la psique del individuo; y g) canales de comunicación empleados en base a los resultados de la investigación de mercado y capacidad de auditorio, pues la comunicación tiene máxima efectividad cuanto menos esfuerzo se requiere del receptor para entenderla y cuanto más noticiable es su transmisión es rápida (ápud Barquero y Barquero, 2006).

\subsection{Los modelos de RR. PP. en la práctica actual y la relación con los medios}

Grunig y Hunt (2003) identifican cuatro modelos de RR. PP. en la práctica actual. Sin embargo, señalan que los profesionales equiparan el ejercicio del modelo "agente de prensa"; prestando mayor atención a la verdad, en comparación al modelo aplicado en sus orígenes, demostrando una preocupación constante en conseguir la atención de los medios de comunicación para sus organizaciones. Por su parte, el modelo "información pública" es utilizado comúnmente por las instituciones públicas, asociaciones sin fines de lucro y empresas. Las organizaciones realizan programas activos de relaciones con la prensa, ofreciendo noticias sobre su organización a los medios de comunicación, mientras que el modelo "asimétrico-bidireccional" se practica comúnmente en empresas de consumo que se desenvuelven en un mercado competitivo.

Finalmente, el modelo "simétrico-bidireccional", se trata de la regulación como catalizador que ha de evidenciar una conducta socialmente responsable a sus reguladores gubernamentales. La práctica las relaciones simétricas bidireccionales con los medios de comunicación confiere una oportunidad para incurrir en prácticas responsables con la prensa, ya que en tanto la organización demuestre apertura, mayor será la posibilidad de una cobertura imparcial y exacta por los medios de comunicación. Sin embargo, podría presentarse el efecto contrario y en perjuicio de la organización. "La comunicación simétrica consiste en dar y tomar. Si los medios se equivocan, proporcióneles información para aclarar el error. Si tiene buenas relaciones con los periodistas a ellos no les importará que usted les refute. Sin embargo, no amenace o ruegue" (Grunig y Hunt, 2003: 345). 
En la actualidad, los cuatro modelos son vigentes y muy utilizados. Las conferencias de prensa, entre otras herramientas de comunicación con los medios, se desarrollan en el modelo simétrico-bidireccional. "Este modelo enfatiza el diálogo. Los actos para la prensa facilitan el diálogo con ella porque los periodistas pueden indagar, sondear y preguntar, y pueden establecer la agenda para sus propias historias" (ibídem: 575).

Figura 2: Características de los modelos de Relaciones Públicas.

\begin{tabular}{|c|c|c|c|c|}
\hline CARACTERÍSTICAS & $\begin{array}{c}\text { AGENTE DE PRENSA / } \\
\text { PUBLICITY } \\
\end{array}$ & $\begin{array}{c}\text { INFORMACIÓN } \\
\text { PÚBLICA } \\
\end{array}$ & $\begin{array}{c}\text { ASIMÉTRICO } \\
\text { BIDIRECCIONAL }\end{array}$ & $\begin{array}{c}\text { SIMÉTRICO } \\
\text { BIDIRECCIONAL } \\
\end{array}$ \\
\hline Objetivo & $\begin{array}{c}\text { Desinformación } \\
\text { (propaganda). }\end{array}$ & $\begin{array}{l}\text { Difusión de la } \\
\text { información. }\end{array}$ & $\begin{array}{l}\text { Persuasión } \\
\text { científica. }\end{array}$ & $\begin{array}{c}\text { Comprensión mutua } \\
\text { (entendimiento } \\
\text { mutuo). }\end{array}$ \\
\hline $\begin{array}{l}\text { Naturaleza de la } \\
\text { investigación }\end{array}$ & $\begin{array}{c}\text { Flujo } \\
\text { unidireccional; } \\
\text { toda la verdad } \\
\text { no es esencial. }\end{array}$ & $\begin{array}{c}\text { Flujo } \\
\text { unidireccional; } \\
\text { la verdad es } \\
\text { importante. } \\
\end{array}$ & $\begin{array}{c}\text { Doble flujo } \\
\text { bidireccional, } \\
\text { efectos } \\
\text { desequilibrados. }\end{array}$ & $\begin{array}{c}\text { Doble flujo } \\
\text { bidireccional, efectos } \\
\text { equilibrados. }\end{array}$ \\
\hline $\begin{array}{l}\text { Modelo de } \\
\text { comunicación }\end{array}$ & Fuente-receptor. & $\begin{array}{l}\text { Fuente- } \\
\text { receptor. }\end{array}$ & $\begin{array}{l}\text { Fuente }=\text { Receptor } \\
\text { Retroalimentación. }\end{array}$ & Grupo $=$ grupo. \\
\hline $\begin{array}{l}\text { Naturaleza de la } \\
\text { investigación }\end{array}$ & $\begin{array}{l}\text { Escasa, } \\
\text { "recuento". }\end{array}$ & $\begin{array}{c}\text { Escasa; } \\
\text { legibilidad y } \\
\text { lectura. }\end{array}$ & $\begin{array}{c}\text { Formativa y } \\
\text { evaluativa de } \\
\text { actitudes. }\end{array}$ & $\begin{array}{l}\text { Formativa y } \\
\text { evaluativa de la } \\
\text { comprensión. }\end{array}$ \\
\hline $\begin{array}{l}\text { Principales } \\
\text { figuras históricas }\end{array}$ & P. T. Barnum. & Ivy L. Lee. & $\begin{array}{l}\text { Edward L. } \\
\text { Bernays. }\end{array}$ & $\begin{array}{c}\text { Bernays, profesores } \\
\text { y destacados } \\
\text { profesionales. }\end{array}$ \\
\hline $\begin{array}{l}\text { Donde se } \\
\text { practican en la } \\
\text { actualidad }\end{array}$ & $\begin{array}{c}\text { Deportes, teatro, } \\
\text { promoción de } \\
\text { productos. }\end{array}$ & $\begin{array}{c}\text { Administración } \\
\text { pública, } \\
\text { asociaciones } \\
\text { sin ánimo de } \\
\text { lucro, empresas } \\
\text { de negocios. }\end{array}$ & $\begin{array}{c}\text { Empresas } \\
\text { competitivas, } \\
\text { agencia de RR. PP. }\end{array}$ & $\begin{array}{l}\text { Empresas reguladas } \\
\text { por la administración, } \\
\text { agencias de RR. PP. }\end{array}$ \\
\hline $\begin{array}{l}\text { \% estimado de } \\
\text { organizaciones } \\
\text { que la ejercen }\end{array}$ & $15 \%$ & $50 \%$ & $20 \%$ & $15 \%$ \\
\hline
\end{tabular}

Fuente: Grunig y Hunt (2003: 73).

\subsection{La calidad de las relaciones}

El papel de las RR. PP. gravitará positivamente dentro de las estrategias generales de la organización si se procura aumentar sus competencias a fin de mantener el equilibrio entre la organización en razón a las demandas de los públicos. Black (2004: 15) afirma que es "mucho más fácil tener éxito en alcanzar unos objetivos concretos, con el apoyo y comprensión del público que contando solo con la oposición o indiferencia pública". Algunos expertos afirman que el valor de las RR. PP. tiene que ser medida a través de un valor monetario y, en especial, de las publicaciones logradas en los medios de comunicación. Para Grunig y otros (2002), la interpretación de los resultados producto de la relación los clasifica en razón a la reputación de productos y/o servicios, pues proporcionan un contexto para el comportamiento de los consumidores, inversionistas, empleados, gobiernos, la 
comunidad, los medios de comunicación y otros públicos estratégicos, en razón al ahorro de dinero al evitar costosos problemas de crisis, de regulación, de litigio y la mala publicidad en razón al retorno de la relación a largo plazo para la inversión económica sostenida en prevenir eventos y/o comportamientos tales como crisis, boicots o litigios y en razón de una relación consistente, pues el buen relacionamiento con algunos grupos puede producir continuo flujo de ingresos.

En la Universidad de Maryland, James Grunig y sus alumnos identificaron dos tipo de relaciones (comunal y de intercambio) y cuatro relaciones de resultado (confianza, control mutuo, satisfacción y compromiso) la cuales definen las relaciones a largo plazo (Gorpe y otros, 2010: 91). Para demostrar que la función de asuntos públicos tiene un valor para toda la organización, Grunig considera necesario desarrollar y utilizar indicadores de resultados a largo plazo que demuestren la calidad de las relaciones. "Estos indicadores se pueden medir para supervisar el efecto general de los programas de relaciones públicas en cada público estratégico y, por tanto, el valor que la función de relaciones públicas tiene que una organización” (Grunig y otros, 2002: 552).

La primera de las formas de relación es la de intercambio donde una de las partes genera beneficios a la otra como una retribución a los beneficios generados mutuamente en el pasado, o como fruto de la expectativa de beneficios retribuidos en un futuro, aunque por lo general, los beneficios no son suficientes para el público, pues ellos esperan de la organización más, tanto para la comunidad y partes interesadas, por lo que, las organizaciones a veces no se beneficia, al menos en el corto plazo.

En la relación comunitaria las dos partes desarrollan acciones que impactan y benefician a los otros, sin que ninguno de los dos esté esperando ningún beneficio a cambio. Este es el principio de las estrategias de responsabilidad social de las organizaciones y, en términos ideales, supondría que ese debería ser el común denominador de todas las relaciones que se gestan entre una organización y sus grupos de interés. Si bien se tratan de relaciones de intercambio (por la expectativa de retribución) a menudo las relaciones toman ese punto de partida y evolucionan a relaciones comunitarias en tanto alcancen su madurez. En ocasiones, este orden puede ser inverso (ibídem). Sin embargo, en la medida que el público perciba que tiene una relación común con una organización, es tal vez el indicador más pura del éxito de la función de gestión de Relaciones Públicas.

Hon y Grunig (1999) han aislado cuatro de estas características, las cuales son de especial importancia para la medición de la calidad de relaciones de la organización con sus públicos:

- Control mutuo: se relaciona con el grado de influencia que cada una de las partes involucradas, en este caso la organización y sus grupos de interés, tienen sobre el otro. A pesar de un cierto grado de desequilibrio de poder es natural en relación a la organización pública, existe la relación más estable y positiva cuando las organizaciones y los públicos tienen algún grado de control sobre la otra (Grunig y otros, 2002). Según Hon y Grunig (1999), el control mutuo es evaluado a partir de reflexiones que deben realizar los 
públicos sobre aspectos como estos: organización interesada en lo que otros dicen, interesada en lo que gente puede decir, considera que las opiniones de la gente son legítimas, que no asume una posición dominante, que realmente escucha lo que gente dice, cuando confiere control de la situación, coopera con los públicos, es consciente de las influencia de los públicos sobre los tomadores de decisiones, tiene en cuenta las opiniones del público para tomar sus más importantes decisiones, propicia espacios para la escucha activa y valora a sus públicos para su fortalecimiento y consolidación.

- Confianza: una de las partes es el nivel de confianza y voluntad de abrirse a la otra parte. La confianza es un concepto complicado, que tiene varias dimensiones subyacentes. Una de ellas es la integridad, la creencia de que una organización hará lo que dice que hará. Una tercera es la competencia, y la creencia de que la organización tiene la capacidad de hacer lo que dice que hará (Grunig y otros, 2002). Según Hon y Grunig (1999) dicha confianza está asociada a aspectos como los siguientes: organización interesada en lo que otros dicen, brinda un trato equitativo y justo, muestra preocupación por sus públicos ante una decisión importante, proyecta confianza para el cumplimiento de sus promesas, exterioriza seguridad en sus habilidades organizacionales, regida por principios sólidos, que no busca inducir al error, dispuesto a dejar que los públicos tomen decisiones y que no se aprovechará de estos, y que goce de reconocimiento y éxito.

- Compromiso: es la medida en que una de las partes considera que la relación vale la pena mantener y promover (Grunig y otros 2002). Según Hon y Grunig (1999), el compromiso está asociado a aspectos como los siguientes: organización interesada en lo que otros dicen, que está interesada en forjar relaciones de largo plazo, que genere una mayor valoración de la relación frente a otras organizaciones similares, que propicie un trabajo en conjunto, que las relaciones estables con la organización sea una prioridad para los públicos, proyectar lealtad y que la organización se encuentra presta en apoyar a sus públicos, con la seguridad de que sí encontrará el respaldo.

- Satisfacción: Es la medida en que una de las partes se siente favorablemente hacia el otro porque las expectativas positivas acerca de la relación se refuerzan. Una relación satisfactoria es aquella en la que los beneficios superan a los costos. Grunig y otros (2002: 553) señalan que la satisfacción también se puede producir "cuando una de las partes considera que la otra parte está participando en medidas positivas para mantener la relación". Para Hon y Grunig (1999) depende de factores como los siguientes: el público está contento con la organización; mutuo beneficio y necesidad de existencia; generar sentimientos de felicidad y disfrute en la interacción con la organización; satisface las necesidades y expectativas; desarrollo de sentimientos de pertenencia, haciendo sentir la importancia a la otra parte y que se perciba que la relación produce hechos importantes. 
Para esta investigación, se evalúa la calidad de las relaciones de los medios periodísticos con una organización universitaria desde las relaciones de intercambio y los niveles de confianza, compromiso y satisfacción, cuya correlación (con la organización como fuente periodística, con los contenidos institucionales de relevancia periodística y con la construcción de la realidad mediática de la organización universitaria) queda demostrada en los resultados.

\title{
5.3. Gestión con los medios de comunicación
}

Conocer los medios, saber cómo trabajar ellos, producir materiales periodísticos, cumplir con sus requerimientos estilísticos, con los plazos e interesar a sus audiencias, es una parte fundamental para el trabajo de las Relaciones Públicas. Cutlip y Center (2001: 391) afirman que

\begin{abstract}
"los profesionales encargados de tratar con los medios, y con las personas clave para el acceso a ellos, deben establecer y mantener relaciones de respeto mutuo, es en esencia una relación de adversarios, ya que los periodistas y las relaciones públicas no están en el mismo negocio, y a menudo no tienen las mismas metas de comunicación".
\end{abstract}

La clave para una estrategia de relaciones con la prensa es hacer que el trabajo del periodista sea fácil, "darle noticias sustanciales, con hechos de los que puede fiarse y todo esto empaquetado convenientemente y entregado a tiempo" (Grunig y Hunt, 2003: 345), tomando en cuenta que desde este enfoque, las RR. PP. y el periodismo comparten similitudes pues "la redacción es una actividad común, tanto en los profesionales de las relaciones públicas como de los de periodismo. Ambos trabajan de forma análoga: entrevistan a personas, recopilan y sintetizan grandes cantidades de información, redactan en un estilo periodístico, y están entrenados para escribir un buen artículo en el último momento" (Wilcox y otros 2006: 19). Además, "para el experto en Relaciones Públicas, la prensa y sobre todo la especializada, es un medio, a la vez que un público al que hay que ponderar adecuadamente a través de los agentes de prensa o bien si se les conoce directamente" (Barquero y Barquero, 2006: 28). Las vinculaciones del relacionista con los medios de comunicación y con los periodistas deben circunscribirse en un clima de respeto a la independencia y libertad de acción para no interferir abusivamente en el trabajo periodístico.

El relacionista público es un puente de recíproco servicio entre los periodistas con los empresarios, directivos para transmitir los anuncios y el quehacer de la organización que la opinión pública debe conocer y, por el contrario, no debe ser una barrera que obstruya el legítimo acceso a una información veraz, completa y oportuna. Lopera (1990: 166) recomienda no tratar "de manipular, con halagos, sobornos o presiones, la integridad informativa de los periodistas o de los medios de comunicación, con la reprobable finalidad de lograr promoción de las entidades a las que sirve o de silenciar ante el público verdades que no convienen a sus intereses particulares". Para Xifra (2014: 204) la principal y más importante regla del profesional a cargo de las relaciones con la prensa, es aquella que no se ciñe solo al momento de requerir la publicación de una información: "si la organización 
tiene valor en términos de noticiabilidad, las relaciones de los directivos y responsables de relaciones públicas con los periodistas (gatekeepers y directores), han de ser constantes".

Nielander (1973) añade los siguientes enunciados que permiten construir una buena relación: a) entrega de comunicados de prensa correctamente escritos, precisos y ajustados a las normas; b) entrega de materiales informativos antes del plazo establecido que permita la formulación de preguntas si ello resulta necesario; $c$ ) presentación de hechos sin superlativos, sin exageraciones y solo se formulan opiniones cuando constituyen parte importante del artículo; d) disponibilidad permanente de los directivos de las organizaciones para brindar declaraciones, sin barreras ni protecciones; $e$ ) disponibilidad permanente de la oficina de RR. PP.; f) no relucir la inversión publicitaria ante los editores periodísticos, no suscitar discusión alguna cuando el artículo no se publica, no quebrar el compromiso de exclusividad con un periodista; $g$ ) el material enviado siempre se dirige a la persona adecuada; $h$ ) las noticias desagradables no siempre se comunican pero cuando la prensa solicita abiertamente una respuesta, esta se facilita; i) las conferencias de prensa se convocan cuando son necesarias e importantes; $j$ ) las fotografías deben enviarse en alta calidad, dotadas de un texto explicativo y responden a las necesidades del editor; $k$ ) envío regular a la prensa de material de apoyo, fotografías para archivo y materiales biográficos de los ejecutivos actualizado; y l) no se debe incurrir en peticiones para retirar una noticia ni tampoco para retractarse, salvo en aquellos casos en los que el error de prensa puede dañar a la organización. Arroyo y Yus (2008) hacen también un recuento de errores que se comenten en la relación con los medios periodísticos, entre los cuales se puede añadir los siguientes:

Figura 3: Errores en la relación con los medios.

\begin{tabular}{|l|l|}
\hline $\begin{array}{l}\text { Enviar una nota } \\
\text { de prensa de } \\
\text { cuatro páginas }\end{array}$ & $\begin{array}{l}\text { Un periodista, por día, lee decenas de notas de prensa, recibe cientos de } \\
\text { llamadas cada semana y es invitado a varias conferencias y/o reuniones } \\
\text { de prensa. El periodista debe procesar toda esa información y seleccionar } \\
\text { aquello que le resulte más atractivo. }\end{array}$ \\
\hline $\begin{array}{l}\text { Tratar de } \\
\text { ganarse a los } \\
\text { periodistas por } \\
\text { el estómago }\end{array}$ & $\begin{array}{l}\text { Para los almuerzos y cenas hay un tiempo pero teniendo en cuenta que los } \\
\text { redactores acuden a la convocatoria para trabajar, recoger información y } \\
\text { adaptarla en la redacción al lenguaje periodístico. El simple agasajo no } \\
\text { conseguirá captar su atención y lograr una buena cobertura }\end{array}$ \\
\hline $\begin{array}{l}\text { Atiborrar de } \\
\text { regalos }\end{array}$ & $\begin{array}{l}\text { Los periodistas en general no se dejan comprar. La potestad de escribir } \\
\text { lo que quiera y como quiera es suya. Es importante tomar en cuenta } \\
\text { que al incurrir en ello, se coloca a la organización en una posición débil } \\
\text { pues induce al periodista a creer que la información que le brindará la } \\
\text { organización carecerá de valor. }\end{array}$ \\
\hline Improvisar & $\begin{array}{l}\text { Es imprescindible preparar las respuestas que se le brindará a la prensa con } \\
\text { un lenguaje claro, directo y breve. }\end{array}$ \\
\hline
\end{tabular}

Fuente: Elaboración propia, basada en Arroyo y Yus (2008). 


\subsection{La relación con los medios periodísticos como estrategia de las RR. PP.}

"Unas buenas relaciones con la prensa requieren un nivel máximo de franqueza y honradez" (Nielander, 1973: 163) y para Tomaello (2005) es preciso conocer a los medios: los periodistas solicitan información inmediata y eso ofrece una mayor posibilidad de tener éxito en la gestión que realiza el relacionista público frente a los medios periodísticos. Sin embargo, esta información debe cumplir ciertos parámetros y valores.

Los profesionales de las RR. PP. desarrollan diversas herramientas que le aseguran un relacionamiento efectivo con los medios de comunicación. Para Xifra (2014) estas responden a técnicas tales como el comunicado escrito y/o audiovisual de prensa, el dosier de prensa, la conferencia o rueda de prensa; organizar encuentros con la prensa o con algunos periodistas clave, en función de sus ámbitos informativos o de los intereses de los medios; prever un encuentro exclusivo entre un representante de la organización y un periodista; planificar una visita o viaje de prensa y mantener una sala virtual de prensa.

Las relaciones con la prensa están presentes en la mayoría de planes y programas de RR. PP. y la elección de las técnicas a utilizar tienen guardan sintonía con la noticiabilidad de la información y a los públicos a los que se busca llegar, de acuerdo con los objetivos planteados de difusión. En ese sentido, el papel de las agencias de noticias (que facilitan el acceso rápido de la información y la diseminan a gran número de medios informativos) resulta un ejercicio estratégico y juicioso, en función de la eficacia de las técnicas para la relación con los medios periodísticos.

Respecto a los aciertos y desaciertos en el trato directo con los periodistas, Tomaello (2005) recomienda que el profesional encargado de la relación con los medios debe saber con qué periodista habla, conocer su especialidad, sus intereses, qué nota está elaborando, qué espera del entrevistado, etc., no confundir su nombre o su medio; no tratar al periodista con familiaridad, no esperar que el periodista busque toda la información para que la cobertura se concrete, creer que el periodista no tiene otras notas que publicar; no apabullar con información inútil, ser razonable con la duración de los encuentros con el periodista, preparar previamente los materiales que se le entregarán, entre los más destacados.

Las relaciones con la prensa tienen una importante dimensión interpersonal. Para Xifra (2014) una relación eficaz con los medios informativos se basa una excelente relación profesional y a menudo personal con el periodista encargado de cubrir el ámbito de actuación de la organización que representamos. Esta relación debe sustentarse en los siguientes principios: 


\section{Figura 4: Principios de la relación con los medios.}

\begin{tabular}{|c|c|}
\hline $\begin{array}{l}\text { Relación directa y sin } \\
\text { presiones }\end{array}$ & $\begin{array}{l}\text { Es recurrente que los responsables de RR. PP. acuden a los periodistas con } \\
\text { mayor jerarquía (editores, jefes de información, directores) para asegurar una } \\
\text { buena cobertura, lo que supone desestimar al periodista comisionado y lograr } \\
\text { un efecto negativo. }\end{array}$ \\
\hline $\begin{array}{l}\text { Agasajar } \\
\text { inoportunamente }\end{array}$ & $\begin{array}{l}\text { Los periodistas cuentan con una rutina poco común y escaso tiempo libre, por } \\
\text { lo que las invitaciones a comer para lograr una publicación no siempre son } \\
\text { efectivas si son continuas, e incluso podrían ser contraproducentes. Cuando } \\
\text { amerite, se extienden felicitaciones por los éxitos profesionales y personales, } \\
\text { así como condolencias. }\end{array}$ \\
\hline $\begin{array}{l}\text { Ser humildes y medir } \\
\text { las palabras }\end{array}$ & $\begin{array}{l}\text { La construcción de la relación con los periodistas se fundamente en la } \\
\text { honestidad. Ofrecer una información maquillada es una práctica que no } \\
\text { funciona y que expone la credibilidad. }\end{array}$ \\
\hline $\begin{array}{l}\text { Responder las } \\
\text { solicitudes de } \\
\text { información }\end{array}$ & $\begin{array}{l}\text { Cuando los periodistas busquen entrevistar a un miembro de la organización } \\
\text { se les debe responder rápidamente. Eso no quiere decir que la respuesta } \\
\text { sea afirmativa sino transmitir un mensaje que les permita organizarse en la } \\
\text { búsqueda de sus fuentes de información. }\end{array}$ \\
\hline $\begin{array}{l}\text { Poseer conocimientos } \\
\text { de cultura general }\end{array}$ & $\begin{array}{l}\text { Por definición, los periodistas son personas con amplia base cultural y al } \\
\text { producirse un encuentro prolongado como un desayuno, un almuerzo o alguna } \\
\text { situación que propicie una conversación, no se hablará siempre de sí mismos } \\
\text { y/o de la organización. }\end{array}$ \\
\hline $\begin{array}{l}\text { Ser capaces de hablar } \\
\text { bien de la competencia }\end{array}$ & $\begin{array}{l}\text { Cuando un ejecutivo es capaz expresar algunos cumplidos a la competencia, } \\
\text { refuerza su imagen de líder empresarial capaz de observar objetivamente el } \\
\text { mercado y tener una visión global de su sector, por lo que el periodista será más } \\
\text { receptivo ante sus palabras. }\end{array}$ \\
\hline $\begin{array}{l}\text { Evitar los envíos } \\
\text { repetitivos y con } \\
\text { excesiva anticipación }\end{array}$ & $\begin{array}{l}\text { Sobre todo por correo electrónico. Algunos profesionales son proclives a utilizar } \\
\text { esta técnica, enviando al periodista, durante una o dos semanas, una serie de } \\
\text { mensajes para anunciar que una noticia importante próxima a realizarse. Aunque } \\
\text { pueda parecer que esta técnica es beneficiosa porque mantiene la atención con el } \\
\text { periodista, no es así porque ellos reciben una multitud de informaciones y este } \\
\text { tipo de mensajes son considerados una pérdida de tiempo. }\end{array}$ \\
\hline $\begin{array}{l}\text { No exteriorizar las } \\
\text { fallas del periodista }\end{array}$ & $\begin{array}{l}\text { Cuando se realiza una entrevista o una conferencia de prensa, es probable } \\
\text { encontrar algún periodista al que traicionará su falta de conocimiento sobre } \\
\text { el tema. Ante esta situación, no se debe hacerle notar su desconocimiento y } \\
\text { contestar con la mayor cortesía y respeto. }\end{array}$ \\
\hline $\begin{array}{l}\text { No reaccionar } \\
\text { negativamente ante } \\
\text { un mal tratamiento } \\
\text { informativo }\end{array}$ & $\begin{array}{l}\text { Es mejor expresar sorpresa y que lo publicado es inexacto al no concordar con } \\
\text { la información que hemos trasmitido, sin otorgarle mayor importancia, pero } \\
\text { expresando la esperanza de que no vuelva a suceder. Lo ideal para el periodista } \\
\text { es resolver estos de la manera más informal posible. }\end{array}$ \\
\hline $\begin{array}{l}\text { La reacción a un } \\
\text { tratamiento ideal de la } \\
\text { información no debe } \\
\text { manifestarse }\end{array}$ & $\begin{array}{l}\text { Si un periodista redacta un artículo muy positivo sobre nuestra organización, } \\
\text { sus productos y/o sus servicios, y lo hace con total libertad e independencia, los } \\
\text { agradecimientos efusivos establecen una relación ambigua. El trabajo del periodista } \\
\text { es informar a la opinión pública y no complacer a una determinada organización. }\end{array}$ \\
\hline $\begin{array}{l}\text { El periodista no será } \\
\text { nuestro gatekeeper } \\
\text { eternamente }\end{array}$ & $\begin{array}{l}\text { La carrera profesional de un periodista se desarrolla y pasado el tiempo, } \\
\text { ocupa otro cargo en el medio o en otro. En este caso, es recomendable seguir } \\
\text { manteniendo la relación con él mientras se establece una nueva relación con } \\
\text { persona encargada de cubrir la actividad de la organización. }\end{array}$ \\
\hline
\end{tabular}

Fuente: Elaboración propia, basada en Xifra (2014: 202-204). 
La relación eficaz entre los medios y las organizaciones exige un tratamiento con profesionalismo, siendo un punto crítico los intereses políticos, económicos y líneas editoriales. Por ello, Xifra (2014) afirma que la función de la información es una estrategia que consiste en difundir los aconteceres o los sucesos, a partir de una selección de procedimientos donde se encuentran involucrados los agentes de la organización, los medios de comunicación y los mensajes.

Por su parte, la función de la comunicación se ubica en la intención de compartir o poner en común una situación, esto es entrar en un proceso de calibración donde existe la intención de generar marcos de referencias similares, entre el o los que emiten un mensaje y entre el o los que reciben. La intención de compartir una misma visión o modelo de acción representación de la realidad es la finalidad de la comunicación.

Para analizar a los medios de comunicación, (Xifra, 2014) afirma que se requiere entender la relación entre los medios de comunicación y los profesionales de las RR. PP., a veces compleja. Los periodistas y los relacionistas se necesitan mutuamente, pues los medios de comunicación necesitan materiales e ideas precedentes de fuentes de RR. PP. y los profesionales necesitan a los medios para exponer sus mensajes.

Desde ese punto, los relacionistas deben recordar algunos aspectos sobre los periodistas: son muy ocupados y al abordar algún tema de interés con ellos debe hacerse de forma sucinta y objetiva; algunos se vanaglorian de tomar decisiones sobre qué temas dar mayor importancia y a cuales no, por lo que, dar énfasis excesivo a un tema puede provocar rechazo en ellos; los periodistas reciben de mejor ánimo las informaciones de las organizaciones sin fines de lucro que de las grandes empresas; los buenos periodistas y los relacionistas públicos competentes se respetan mutuamente y trabajan por el bien común.

\section{Resultados}

Habiendo administrado el cuestionario, se procedió a trabajar la estadística descriptiva para determinar el estado de las variables, dimensiones e indicadores. Se aplicó el test de Kolmogorov-Smirnov para medir la normalidad de la distribución de las variables y así decidir el estadístico de correlación; con un nivel de significancia de 5\% y con nivel de confianza para la media del $95 \%$. 
Figura 5: Percepción del nivel de confianza.

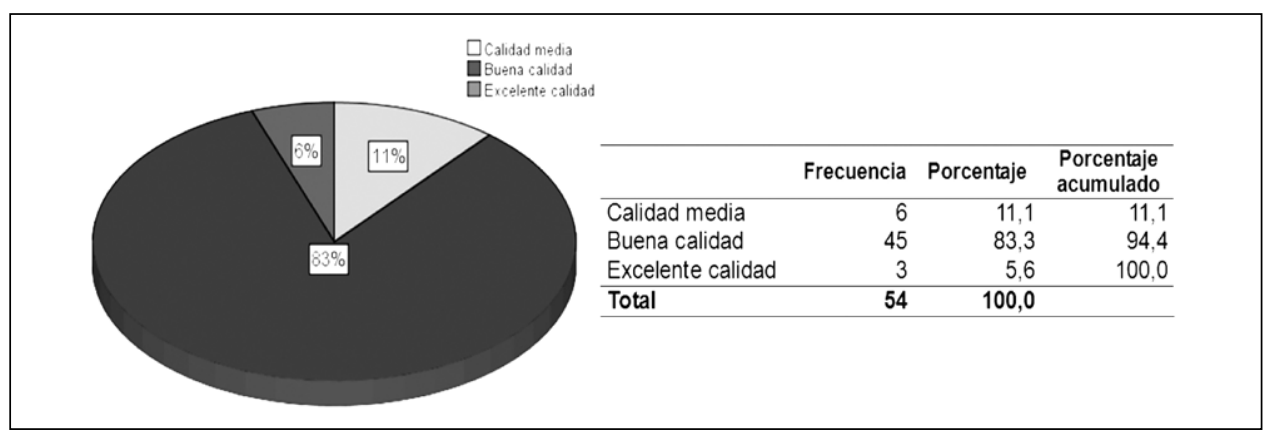

Fuente: Elaboración propia.

Según los datos extraídos a partir de las encuestas realizadas, se sabe que con respecto a la percepción del nivel de confianza en una organización de educación universitaria, el $83 \%$ de los encuestados opina que es de buena calidad, mientras que el $11 \%$ cree que tiene calidad media, y por ultimo el $6 \%$ opina que es de excelente calidad.

Figura 6: Percepción del nivel de compromiso.

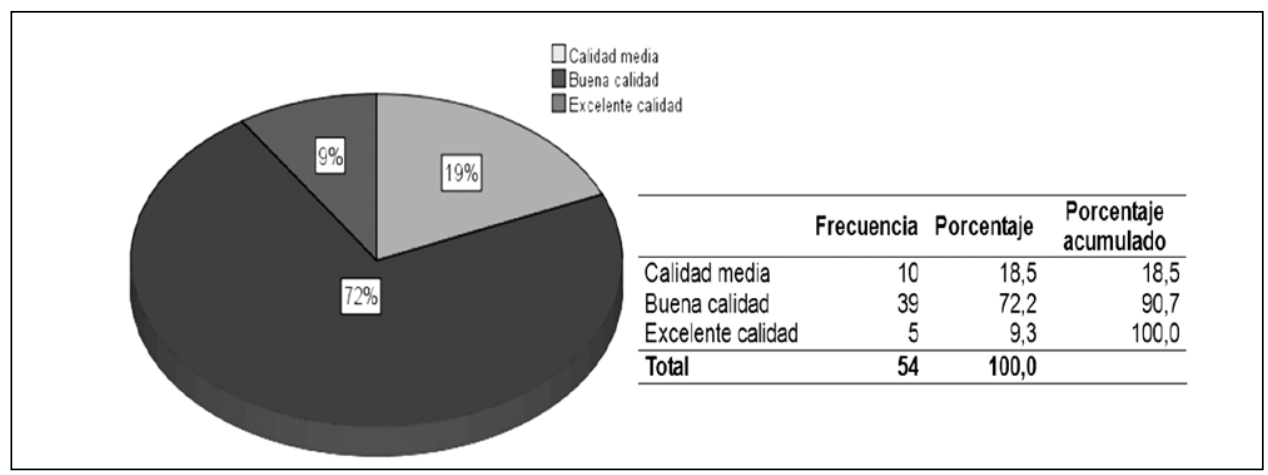

Fuente: Elaboración propia.

Según los datos extraídos a partir de las encuestas realizadas, se sabe que con respecto a la percepción del nivel de compromiso organización de educación universitaria, el $72 \%$ de los encuestados opina que es de buena calidad, mientras que el 19\% cree que tiene calidad media, y por ultimo el $9 \%$ opina que es de excelente calidad. 
Figura 7: Percepción del nivel de satisfacción.

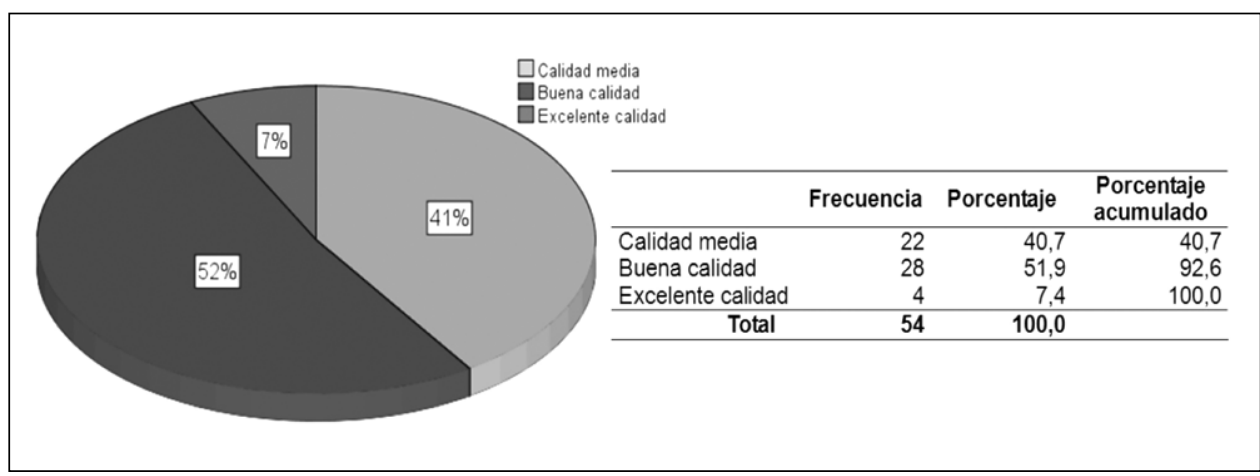

Fuente: Elaboración propia.

Según los datos extraídos a partir de las encuestas realizadas, se sabe que con respecto a la percepción del nivel de satisfacción respecto una organización de educación universitaria, el $52 \%$ de los encuestados opina que es de buena calidad, mientras que el $41 \%$ cree que tiene calidad media, y por ultimo el $7 \%$ opina que es de excelente calidad.

Figura 8: Organización de educación universitaria como fuente periodística.

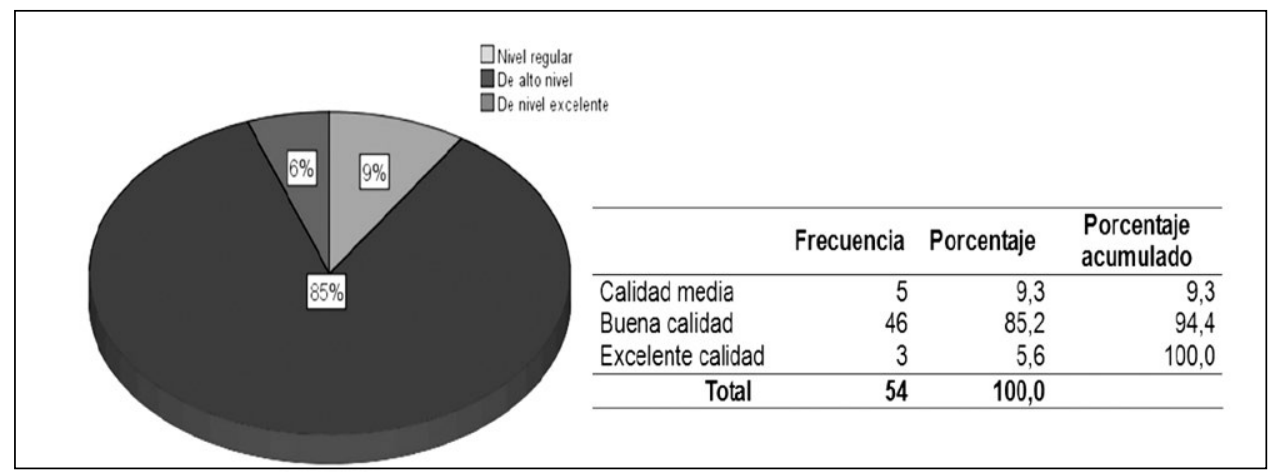

Fuente: Elaboración propia.

Según los datos extraídos a partir de las encuestas realizadas, se sabe que con respecto organización de educación universitaria como fuente periodística, el 85\% de los encuestados opina que tiene un alto nivel, mientras que el $9 \%$ cree que tiene un nivel regular, y por ultimo el $6 \%$ opina que tiene un nivel excelente. 
Figura 9: Relevancia periodística de los contenidos enviados por la organización de educación universitaria.

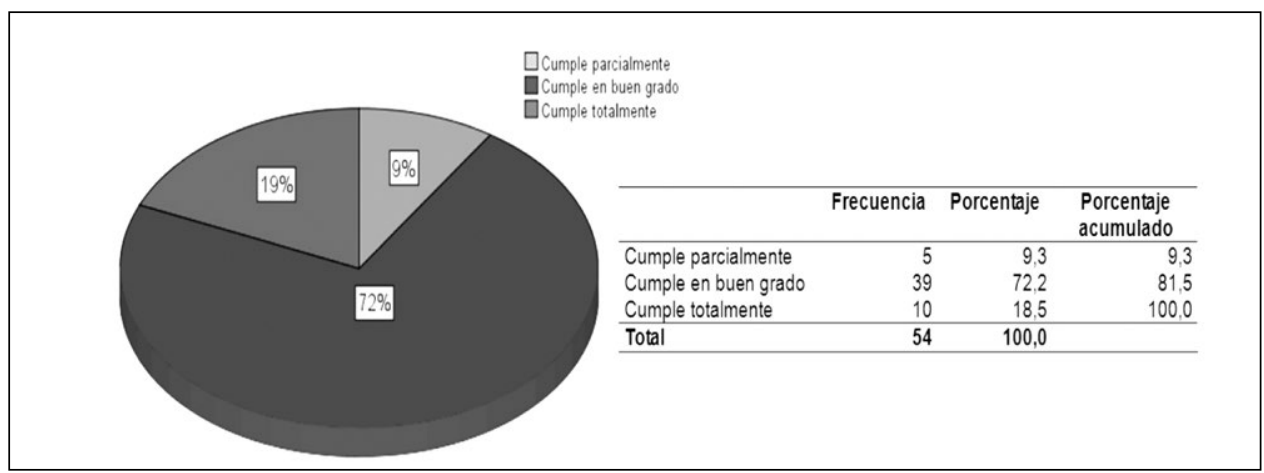

Fuente: Elaboración propia.

Según los datos extraídos a partir de las encuestas realizadas, se sabe que con respecto a la relevancia periodística de los contenidos enviados por la organización de educación universitaria, el $72 \%$ de los encuestados opina cumple en buen grado, mientras que el 19\% cree que cumple totalmente, y por ultimo el $9 \%$ opina que cumple parcialmente.

Figura 10: Realidad mediática de la organización de educación universitaria

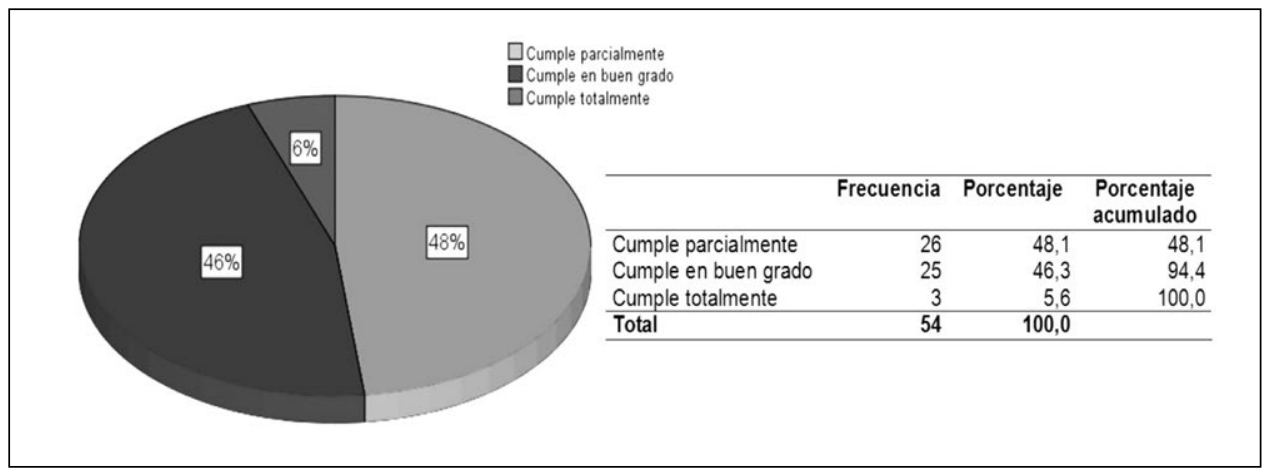

Fuente: Elaboración propia.

Según los datos extraídos a partir de las encuestas realizadas, se sabe que con respecto a la realidad mediática de la organización de educación universitaria, el $48 \%$ de los encuestados opina que cumple parcialmente, mientras que el $46 \%$ cree que cumple parcialmente y, por ultimo, el $6 \%$ opina que cumple totalmente.

\section{Contraste de las hipótesis}

Para el análisis descriptivo de los resultados de las hipótesis, se hizo uso de tablas de contingencia para observar con mayor detalle la opinión de los encuestados. Luego se 
aplicó la prueba de Kolmogorov-Smirnov de las variables. Sin embargo, en todas ellas no se halló una distribución normal, por lo que se determinó utilizar la prueba de correlación no paramétrica de Rho de Spearman, obteniendo los siguientes resultados:

7.1. Análisis de los resultados de la hipótesis general: respecto a los contenidos periodísticos, el $9.3 \%$ cree que se cumple parcialmente y que la calidad de las relaciones es media, mientras que el $13 \%$ cree que los contenidos periodísticos se cumplen en buen grado, pero estos tienen calidad media. También se sabe que para los encuestados, el $72.2 \%$ de los contenidos periodísticos cumplen en buen grado y hay una buena calidad de relaciones, y por último el $5.6 \%$ de los encuestados cree que los contenidos periodísticos cumplen totalmente y que la calidad de relaciones son excelentes.

Al contrastar estos resultados (mediante la prueba de Kolmogorov-Smirnov y la prueba de Rho de Spearman) se demuestra que a un nivel de significancia del 5\% hay correlación significativa ya que el p-valor es 0.000 , con un buen nivel de relación sign ificativa, ya que hay un nivel de correlación de $71.8 \%$, lo cual es un claro indicador del alto nivel existente entre las variables.

7.2. Análisis de los resultados de la hipótesis específica: el nivel de confianza de los medios periodísticos con la organización de educación universitaria tendría relación significativa para considerarla como fuente periodística.

Respecto a la confianza, el $7.4 \%$ cree que tiene calidad media y que la fuente periodística tiene nivel regular, mientras que el $3.7 \%$ cree que la confianza tiene calidad media y la fuente periodística es de alto nivel. También se sabe que el $1.9 \%$ de los encuestados asume que el nivel de la confianza es bueno, pero que las fuentes periodísticas son regulares. Por otro lado, el $81.5 \%$ de los encuestados cree que la confianza es de buena calidad y que la fuente periodística es de alto nivel. Por último, el 5.6\% de los encuestados cree que la confianza es excelente y que las fuentes periodísticas son de excelente nivel.

Al contrastar estos resultados (mediante la prueba de Kolmogorov-Smirnov y la prueba de Rho de Spearman) a un nivel de significancia del 5\% hay correlación significativa, ya que el p-valor es 0.000 , con un buen nivel de relación entre las variables nivel de confianza de los medios de comunicación y la organización de educación universitaria como fuente periodística. Estos resultados demuestran que el nivel de confianza de los medios impresos tiene relación significativa, ya que se correlacionan en un $81.6 \%$, lo cual es un indicador claro de la relación existente entre estas dos variables.

7.3. Análisis de los resultados de la hipótesis específica: el nivel de compromiso de los medios periodísticos tendría relación significativa con la construcción de la realidad mediática de la organización de educación universitaria.

Respecto al compromiso, el $16.7 \%$ cree que tiene calidad media y que la realidad mediática cumple parcialmente, mientras que el $1.9 \%$ cree que el compromiso tiene calidad media y que la realidad mediática cumple en buen grado. También se sabe que el 
$31.5 \%$ de los encuestados cree que el nivel de compromiso es de buena calidad, pero que la realidad mediática cumple parcialmente. Por otro lado, el $40.7 \%$ de los encuestados cree que el compromiso es de buena calidad y que la realidad mediática cumple en buen grado. Asimismo, el 3.7\% de los encuestados asume que el compromiso es de excelente calidad, pero la realidad mediática cumple en buen grado. Por último, el 5.6\% de los encuestados cree que el compromiso es excelente y que la realidad mediática se cumple totalmente.

Al contrastar estos resultados (mediante la prueba de Kolmogorov-Smirnov y la prueba de Rho de Spearman) a un nivel de significancia del 5\% se puede afirmar que existe correlación significativa ya que el p-valor es 0.000 , siendo esta una relación buena entre las variables nivel de compromiso de los medios de comunicación y construcción de la realidad mediática de la organización de educación universitaria. Por tanto, queda probado que existe relación significativa, ya que se correlacionan en un $54.6 \%$, lo cual es un indicador claro de la relación existente entre estas dos variables.

7.4. Análisis de los resultados de la hipótesis específica: El nivel de satisfacción de los medios periodísticos tendría relación significativa con la relevancia periodística de los contenidos enviados por la organización de educación universitaria.

Respecto a la satisfacción, el $9.3 \%$ de los encuestados cree que tiene calidad media acompañado de una relevancia periodística que cumple parcialmente. Un $31.5 \%$ cree que la satisfacción tiene calidad media, pero que la relevancia periodística cumple en buen grado. Por otro lado, el $40.7 \%$ de los encuestados cree que la satisfacción tiene buena calidad y que la relevancia periodística cumple en buen grado, mientras que el $11.1 \%$ cree que la satisfacción tiene buena calidad y que la relevancia periodística cumple totalmente. Por último, el $7.4 \%$ cree que la satisfacción es de excelente calidad y que la relevancia periodística cumple totalmente.

Al contrastar estos resultados (mediante la prueba de Kolmogorov-Smirnov y la prueba de Rho de Spearman) a un nivel de significancia del 5\% se puede afirmar que existe correlación significativa, ya que el p-valor es 0.000 , siendo esta una buena correlación entre las variables el nivel de satisfacción de los medios periodísticos y relevancia periodística de los contenidos enviados por la organización universitaria. Queda demostrado que el nivel de satisfacción de los medios de comunicación se relaciona significativamente con la relevancia periodística de los contenidos sobre la organización de educación universitaria, ya que se correlacionan en un $60.3 \%$, lo cual es un indicador claro de la relación existente entre estas dos variables

\section{Conclusiones}

Las relaciones con los medios periodísticos se constituyen en una de las estrategias de RR. PP. más usadas para proyectar la imagen institucional hacia la opinión pública. Sin embargo, la eficiencia, eficacia y efectividad de esta relación depende del tipo de organización, su 
reputación y los programas así como estrategias de RR. PP. que se orienten a los medios periodísticos en sintonía con las acciones relacionales y comunicacionales dirigidas a otros públicos.

Los medios periodísticos buscan fuentes fidedignas, creíbles, confiables y, debido a la segmentación de sus espacios, los contenidos y voceros especializados gozan de especial valor. En ese sentido, las universidades poseen una riqueza de conocimiento y sus contenidos académicos, especializados y científicos pueden ser tratados y adecuados según los valores y criterios noticiosos según el medio con el cual se mantiene la relación colaborativa.

La investigación que aborda el presente artículo comprueba la correlación existente entre la calidad de las relaciones (medida desde los niveles de confianza de los medios periodísticos con la organización universitaria como fuente periodística), los niveles de satisfacción de los medios periodísticos (con la relevancia periodística de los contenidos enviados por la organización universitaria) y los niveles de compromiso del medio por construir la realidad mediática de la organización universitaria con mayor acercamiento a la imagen que esta busca proyectar.

De esta manera, las oficinas encargadas de RR. PP. de las organizaciones universitarias se convierten en la fuente de información para los medios periodísticos, cuya efectividad radica en la confianza que estos generen con los medios y periodistas para el recojo de la información que será desarrollada y publicada, lo que finalmente se convierte en la realidad mediática de las organizaciones.

La difusión de los conocimientos científicos de una organización universitaria también es propicia para el desarrollo de encuentros, capacitaciones, mesas de debate, entre otros eventos que permitan a los periodistas nutrirse de conocimiento especializado, ya sea según sus intereses laborales, en razón a la sección periodística donde se desarrolle o para su crecimiento profesional en los temas vinculados al periodismo y nuevas tecnologías, así como el desarrollo herramientas que le permita efectuar su labor a la vanguardia. Estas acciones permiten que los niveles de satisfacción de los medios hacia la organización se incrementen, pues la colaboración abarcaría tanto el ámbito laboral y profesional de los periodistas y de los medios de comunicación, al proporcionar conocimiento especializado como contribución al ejercicio periodístico en sí, y no motivado precisamente por algún tema que la organización busque difundir en el corto plazo.

Las organizaciones universitarias cada vez son conscientes de elaborar y ejecutar planes y estrategias orientadas a la relación con los medios de comunicación de forma sostenible en el tiempo y no solo cuando se presente un evento y/o programa académico que se desee difundir, desde los ámbitos offline y online. El fortalecimiento de los lazos de confianza con los medios periodísticos desde las universidades se encuentra también en la selección y disponibilidad del staff de vocería, el cual esté conformado por los especialistas más destacados en sus especialidades, en los contenidos producidos por 
los docentes e investigadores, así como los resultados obtenidos en las investigaciones científicas que las universidades realicen. La vasta información que se puede encontrar puede ser seleccionada y luego presentada a través de una sala de prensa virtual, haciendo uso de las herramientas que el entorno web y las redes sociales ofrecen.

Las organizaciones universitarias, como cualquier otra, está en la obligación de asumir y responder los compromisos pactados con los medios de comunicación, en razón a la relación colaborativa, de forma reactiva y proactiva con estos, proponiendo contenidos noticiables, fundamentados en la investigación. Asimismo, explotar la infraestructura y atributos que poseen las universidades para demostrar los planteamientos y/o resultados vertidos en sus investigaciones. Finalmente, responder a las necesidades de los medios de comunicación, en torno al conocimiento brindado desde dos vertientes: a) proveer de contenidos de interés, con valores noticiosos y que cumplan con los criterios de los medios al que se envía; y b) proveer de conocimientos a los medios periodísticos, a través de sus periodistas, para la profesionalización, ejercicio ético y actualizado, de modo tal que se contribuye con el desarrollo la profesión.

Esta investigación concluye en que la calidad de las relaciones con los medios periodísticos tiene una relación significativa con las publicaciones periodísticas sobre la organización universitaria, es decir, están relacionadas directamente proporcional, tanto las buenas relaciones con el incremento de número de publicaciones de la institución universitaria en los medios periodísticos.

El nivel de confianza de los medios periodísticos tiene una relación significativa con la organización universitaria como fuente periodística, es decir, mientras los medios confíen más en la organización, mayor será el número de veces que acudan o que la refieran como fuente periodística. Por su parte, el nivel de compromiso de los medios periodísticos tiene relación significativa con la construcción de la realidad mediática de la organización universitaria, es decir, si los compromisos asumidos por la universidad son cumplidos con los medios periodísticos, más cercano a la realidad concreta será la realidad mediática de la organización, según el medio periodístico.

Finalmente, el nivel de satisfacción de los medios impresos se relaciona significativamente con la relevancia periodística de los contenidos enviados por la organización universitaria, es decir, mientras mayor sea la relevancia periodística de los contenidos proporcionados por organización universitaria, mayor será el nivel de satisfacción. En este nivel, también está inmersa la satisfacción producida por los medios ante los contenidos que la institución universitaria ofrezca para el desarrollo del medio de comunicación y sus periodistas, por ser una institución formadora de profesionales en los niveles de pregrado, postgrado y especialización.

En la relación con los medios periodísticos, las RR. PP. permiten generar una cultura de confianza, apoyada con información veraz y creíble, como resultado de un comportamiento ético y moral, siendo este el caso, desde las organizaciones universitarias. 


\section{Fuentes consultadas}

Arroyo, L. y Yus, M. (2008). Los cien errores de la comunicación de las organizaciones. Madrid: ESIC.

Barquero, J. y Barquero, C. (2006). Relaciones Públicas Estratégicas. Barcelona: Gestión 2000.

Biagi, S. (2006). Impacto de los medios, introducción a los medios masivos de comunicación. México D. F.: International Thomson Editores.

Black, S. (2004). ABC de las Relaciones Públicas. Barcelona: Ediciones Gestión 2000. Cortez, K. (2014). La calidad de las relaciones institucionales universitarias en relación con los contenidos publicados en los medios periodísticos [tesis de maestría]. Lima: Universidad de San Martín de Porres, Facultad de Ciencias de la Comunicación, Turismo y Psicología.

Cutlip, S. y Center, A.

(2001). Relaciones Públicas eficaces. Barcelona: Ediciones Gestión 2000.

_(1978). Effective Public Relations. Nueva Jersey: Prentice-Hall.

Boiry, P. (1998). Relaciones Públicas o Estrategia de la confianza. Barcelona: Ediciones Gestión 2000.

D’Adamo, O.; García, V. y Freidenberg, F. (2007). Medios de comunicación y opinión pública. Madrid: McGraw-Hill.

Ferrari, M. y França, F. (2012). Gestión de las Relaciones Públicas para el éxito de las organizaciones. Lima: USMP.

García, V. y Gutiérrez, L. (2011). Manual de géneros periodísticos. Bogotá: Universidad de La Sabana.

Gorpe, S. y otros (2010). Las Nuevas Relaciones Públicas. Lima: USMP.

Grunig, J. y Hon, L. (1999). "Guidelines for Measuring Relationship in Public Relations". Institute for Public Relations. Extraída el 26/VIII/2015 desde http://www.aco.nato.int/ resources/9/Conference\%202011/Guidelines_Measuring_Relationships[1].pdf

Grunig, J. y Hunt, T. (2003). Dirección de Relaciones Públicas. Barcelona: Ediciones 2000. Grunig, L.; Grunig, J. y Dozier, D. (2002). Excellent Public Relations and Effective Organizations: a Study Communication Management in three countries. Nueva Jersey: Lawrence Erlbaum Associates.

La Rosa, A. (2013). Construcción de la agenda mediática, una mirada al interior de la comunicación. Lima: USMP. 
Lopera, A. (1990). Ética del periodismo y la comunicación. Antioquia: Universidad de Antioquia.

Nielander, W. (1973). Práctica de las Relaciones Públicas métodos para crear una imagen atractiva de la empresa. Barcelona: Hispano Europea.

Pereira, J. y Flores, F. (2010). Relaciones Públicas fundamentos, praxis y comunicación corporativa en el tercer milenio. Lima: Editorial San Marcos.

Pérez, R. y Solórzano, E. (1999). Las Relaciones Públicas Superiores, una nueva pedagogía. Lima: USMP.

Tomaello, F. (2005). Cómo ser asesor de prensa. Buenos Aires: Longseller.

Wilcox, D.; Cameron, G. y Xifra, J. (2006). Relaciones Públicas estrategias y tácticas. Madrid: Pearson Educación.

Xifra, J. (2014). Manual de las Relaciones Públicas e Institucionales. Madrid: Editorial Tecnos. 